\title{
Effect of Cold Plasma Treatment on FRP Surface: The Behavior of FRP/Wood Interfacial Adhesion
}

\author{
Hui Yuan, Shijie Shen, Chen Qiu, Shuping Zhao \\ Key Laboratory of Wood Science and Engineering, Ministry of Education, \\ Beijing Forestry University, \\ Beijing, China
}

\begin{abstract}
In this work, FRP panel surface was treated by 12 plasma techniques formed by a pairwise combination of four power consumptions $(300 \mathrm{~W}, 400 \mathrm{~W}, 500 \mathrm{~W}$, and $600 \mathrm{~W})$ and three transmission velocity $(2.5 \mathrm{~m} / \mathrm{min}, 5.0 \mathrm{~m} / \mathrm{min}$, and $7.5 \mathrm{~m} / \mathrm{min}$ ) respectively, and then adhere to timbers. According to delamination test dates, 7 of 12 specimen groups meet the requirement. Shear strength at dry state of composite FRP/wood -was improved. Mode $G_{\text {IIC }}$ of $4 E N F$ for the composite fracture toughness test was inferred in this paper. Variance analysis results demonstrated that power and velocity interaction has significant influence on delamination properties of FRP-wood interface, and power has significant influence on shear strength and fracture toughness. Considering strength and toughness synthetically, the optimized process of plasma treatment on FRP surface could be concluded, which power consumption was $300 \mathrm{~W}$, transmission speed was $5.0 \mathrm{~m} / \mathrm{min}$. With this process, the properties of the composite interface are as following: the average shear strength at dry state was $9.46 \mathrm{MPa}, 6.49 \mathrm{MPa}$ at wet state, the $G_{\text {IIC }}$ was $0.94 \mathrm{~kJ} / \mathrm{m}^{2}$, and the average delamination ratio was $1 \%$ and $3 \%$ after soaked in normal and boiling water, which are all meet the request of standard.
\end{abstract}

Keywords-G-FRP; plasma treatment; glulam; interfacial adhesion; delamination properties; shear strength; fracture toughness

\section{INTRODUCTION}

Fiber Reinforced Plastic (FRP) can meet the demands of modern engineering structures with characteristic of large span, heavy load, light, enduring, etc. due to its outstanding properties such as high strength to weight ratio, corrosion resistance and anti-fatigue, etc. [1].

In FRP reinforced Wood composite: the FRP can effectively improve glulam mechanical strength especially flexural properties [2]. Dagher found the flexural strength with FRP/glulam composite could be increased by $56 \%$ at most when low and medium wood were used and beams reinforced with FRP on the tension side in the experimental study [3]. Bending stiffness and strength of composites were increased by $18 \%$ and $26 \%$, respectively, when FRP reinforcement ratio

is $3 \%$ [4]. Besides, pre-stress FRP sheets as external reinforcement of wood members can obtain more than $24 \%$ increasing of bending properties compare to not [5]. However, a number of studies have shown that delamination in the end position of composites is ubiquitous when FRP sheets pre-stressed [6-10].
It is important to note an effective interface cohesion is required in an excellent composite to obtain better stress transfer and crack-resistant [11]. According to FRP/Wood composite structure, five possible failure modes of FRP/wood interface are described as follows: failure of wood, interface between wood and adhesive, adhesive, interface between adhesive and FRP and FRP. In fact, it happens with more than one failure modes as usually. But since untreated FRP surface exhibit very low wettability, stress concentrates at interface between FRP and adhesive of FRP/wood composite which under loading [12]. Oporto studied to increase wettability of FRP surface with pre-treatment of cold plasma, and the results shown that shear strength of interface between FRP and WPC (Wood plastic composite) was improved to $200 \%$ [13]. What is more, Glass-FRP surface - treated by cold plasma - contact angle decreased from $98 \mathrm{C}$ to $19 \mathrm{C}$, which means a higher surface energy obtained, and the same result shown through test analysis of AFM and XPS [14].

Interface fracture is a typical failure mode of composite system, and the main reason for development of fracture is delamination - the sliding crack [15]. Four point bend end - notched flexure specimen (4ENF) were used appropriately for fracture toughness test of composite due to their three aspects of advantages: designed easily; crack propagation stability under loading; just measured critical load since the critical energy release rate of $4 \mathrm{ENF}$ is not affected by the influence of crack length [16]. The aim of our investigation is to evaluate bonding properties of FRP/wood - pretreated with cold plasma on FRP surface - composite through various test analysis include delamination properties, shear strength and fracture toughness synthetically, and obtain the optimal process finally.

\section{EXPERIMENTS}

\section{A. Materials and Equipment}

FRP: Glass fiber reinforced plastic with size of 1060 $\mathrm{mm} \times 51 \mathrm{~mm} \times 20 \mathrm{~mm}$.

Wood: Camphor pine with density of $0.5 \mathrm{~g} / \mathrm{cm}^{3}$, moisture rate of $0.8 \%$ and size of $1060 \mathrm{~mm} \times 51 \mathrm{~mm} \times 20 \mathrm{~mm}$ provided by Dalian Shuanghua Factory (China). 
Adhesive: One component polyurethane - PURBOND

HB S709 - provided by Dalian Shuanghua Factory (China).

\begin{tabular}{cccccccccccccc}
\hline \multicolumn{2}{c}{ Number } & P1 & P2 & P3 & P4 & P5 & P6 & P7. & P8 & P9. & P10 & P11 & P12 \\
\hline Cold Plasma & Power $/ \mathrm{w}$ & 300 & 300 & 300 & 400 & 400 & 400 & 500 & 500 & 500 & 600 & 600 & 600 \\
treatment & Speed $(\mathrm{m} / \mathrm{min})$ & 2.5 & 5.0 & 7.5 & 2.5 & 5.0 & 7.5 & 2.5 & 5.0 & 7.5 & 2.5 & 5.0 & 7.5
\end{tabular}

Figure 1. Technological parameters of cold plasma treatment on FRP surface.

\begin{tabular}{|c|c|c|c|c|c|c|c|c|c|c|c|c|c|}
\hline Num & & P1. & P2. & P3. & P4. & P5. & P6. & P7. & P8. & P9. & P10. & P11. & P12. \\
\hline \multicolumn{14}{|c|}{ Specimens soaked in water with temperature of $10 \mathrm{C}$ to $20 \mathrm{C}$. } \\
\hline Delamination & Average & 12. & 1. & 1. & 0 & 30. & 0 & 3. & 11. & 0 & 7. & 4. & 3. \\
\hline ratio $(\%)$ & max value & 87. & 14. & 21. & 0. & 100. & 0 & 24. & 59. & 9. & 52 & 33. & 35 . \\
\hline \multicolumn{14}{|c|}{ Specimens soaked in boil water. } \\
\hline Delamination & Average & 1. & 3. & 4. & 3. & 20 & 1. & 12. & 10. & 1. & 5. & 4. & 2. \\
\hline ratio $(\%)$ & max value & 26. & 33. & 42 & 39. & 78 & 7. & 94. & 62. & 14. & 55. & 44. & 18. \\
\hline
\end{tabular}

Figure 2. Results of delamination test.

Plasma machine and universal mechanical testing machine provided by Beijing Forestry University (China).

\section{B. Cold plasma Treatment}

Firstly, the FRP surface was treated by cold plasma with variable quantities of power and speed of plasma machine respectively, and the technological parameters are shown in Figure 1.

Secondly, in proper order of wood after FRP after wood composites were glued with adhesive quantity of $180 \mathrm{~g} / \mathrm{m}^{2}$. Then pressed the composites and made sure the temperature was $20^{\circ} \mathrm{C}$, the relative humidity was $65 \%$ and time for press lasted $175 \mathrm{~min}$ at least. Finally, composites were laid for 10 hours at temperature of $20^{\circ} \mathrm{C}$ after released.

\section{RESULTS AND DISCUSSION}

\section{A. Delamination Properties}

According to GB/T 26899 (China national standard for structural glulam), each composite were cut into 12 specimens with size of $75 \mathrm{~mm} \times 50 \mathrm{~mm}$ and each specimen's quality obtained. Half specimens soaked in water $\left(10-20^{\circ} \mathrm{C}\right)$ for $24 \mathrm{~h}$ and the rest of specimens soaked in water $\left(10-20^{\circ} \mathrm{C}\right)$ for $1 \mathrm{~h}$ followed by $4 \mathrm{~h}$ in boil water, and then all of them transferred into constant temperature $\left(70^{\circ} \mathrm{C}\right)$ drying box. The specimens were taken out until their qualities as 1.0-1.1 times as initial. At last, delamination ratio obtained through measurement and calculation as Figures 2 and 3 show.

The standard of delamination ratio is equal or lower than $5 \%$, and 7 of 12 groups meet the requirement. The data of delamination appears regularly, so variance analysis demanded:

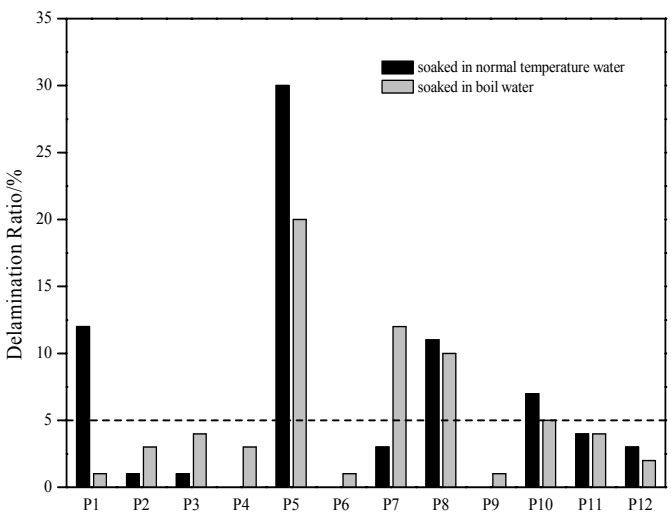

\begin{tabular}{|c|c|c|c|c|c|c|}
\hline Test method & \multicolumn{3}{|c|}{ Soaked in normal water } & \multicolumn{3}{|c|}{ Soaked in boil water } \\
\hline Source of variation & Power $/ W_{2}$ & Speed/MMin & Interaction & Power $/ \mathrm{W}$ & Speed/M/Min & Interaction \\
\hline Fratio & 2.50 & 14.50 & 13.39 & 2.74 & 7.29 & 4.16 \\
\hline F standard value & 2.76 & 3.15 & 2.25 & 2.76 & 3.15 & 2.25 \\
\hline Significant & $\star$ & $\star \star$ & $\star \star \star \star t$ & 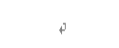 & $\star$ & $\star$ \\
\hline
\end{tabular}

Figure 4. Variance analysis of delamination test date. 
According to Figure 4, factors of speed and interaction influenced the delamination ratio significantly especially on specimens soaked in normal water as the table shows. Besides, wood density, angle of laminated texture and resin infiltration of wood are important reasons for delamination according to observe the failure specimens.

\section{B. Shear Strength}

According to GB/T 26899 (China national standard for structural glulam), each composite was cut into 12 specimens with exposed interface between wood and FRP as appropriate size as standard demand and each specimen's quality obtained. Half specimens soaked in water $\left(10-20^{\circ} \mathrm{C}\right)$ for $24 \mathrm{~h}$ and then shear strength tested immediately at wet state according to GB 5005, and the others' shear strength tested at dry state. At last, shear strength date, wood failure ratio and retention of shear strength at wet state obtained through measurement and calculation as Figures 5 and 6 show.

\begin{tabular}{|c|c|c|c|c|c|c|c|c|c|c|c|c|}
\hline Number & $\mathrm{Pl}$ & $\mathrm{P} 2$ & $\mathrm{P} 3$ & $\mathrm{P} 4$ & $\mathrm{P} 5$ & $\mathrm{P} 6$ & $\mathrm{P} 7$ & P8 & $\mathrm{P} 9$ & $\mathrm{P} 10$ & P11 & $\mathrm{P} 12$ \\
\hline \multicolumn{13}{|c|}{ Specimens tested at diy state } \\
\hline Shear strength $\mathrm{MPa}$ & 9.43 & 9.46 & 7.10 & 7.75 & 8.16 & 7.19 & 8.82 & 7.75 & 7.62 & 10.45 & 8.79 & 8.68 \\
\hline Wood failure ratio $/ \%$ & 75 & 71 & 93 & 84 & 62 & 86 & 93 & 80 & 94 & 83 & 59 & 90 \\
\hline \multicolumn{13}{|c|}{ Specimens tested at wet state } \\
\hline Shear strength $/ \mathrm{MPa}$ & 5.58 & 6.49 & 5.66 & 4.96 & 4.55 & 6.16 & 5.13 & 4.57 & 5.02 & 5.68 & 5.83 & 6.27 \\
\hline Wood failure ratio $/ \%$ & 37 & 31 & 74 & 75 & 35 & 67 & 48 & 33 & 55 & 31 & 41 & 69 \\
\hline Strength retention $/ \%$ & 59.17 & 68.59 & 79.77 & 63.96 & 55.76 & 85.68 & 58.08 & 59.02 & 65.89 & 54.37 & 66.26 & 72.24 \\
\hline
\end{tabular}

Figure 5. Results of shear strength test.

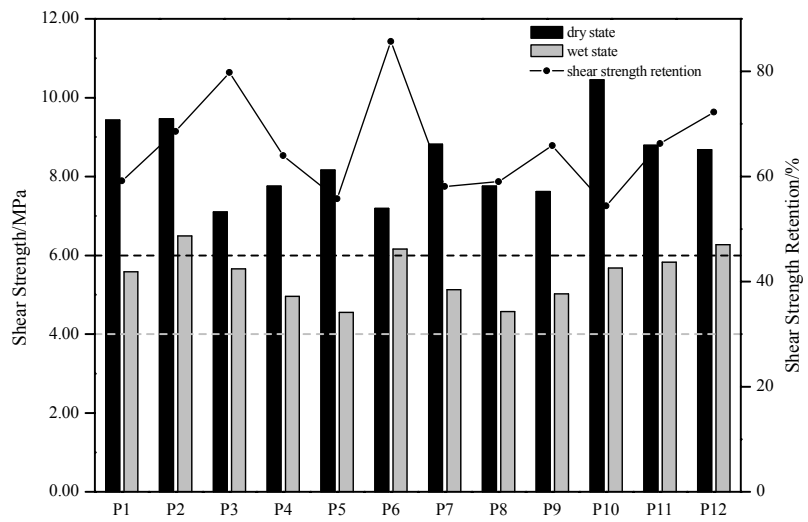

Figure 6. Shear strength dates analysis.

\begin{tabular}{ccccccc}
\hline Test method & \multicolumn{3}{c}{ Tested by dry state } & \multicolumn{3}{c}{ Tested by wet state } \\
\hline Source of variation & Power/W & Speed/M/Min & Interaction & Power/W & Speed/M/Min & Interaction \\
F ratio & 6.44 & 9.39 & 1.86 & 6.21 & 1.96 & 2.34 \\
F standard value & 2.76 & 3.15 & 2.25 & 2.76 & 3.15 & 2.25 \\
Significant & $\star$ & $\star$ & & $\star$ & & $\star$ \\
\hline
\end{tabular}

Note: $a=0.05$

Figure 7. Variance analysis of shear strength test date.

The standard of shear strength is equal or more than $6 \mathrm{MPa}$ and $4 \mathrm{MPa}$ for dry state and wet state test, respectively. All groups meet the requirement. The maximum value of dry state shear strength appeared when plasma machine's power is $600 \mathrm{~W}$ and speed is $2.5 \mathrm{~m} / \mathrm{min}$ at group P10. Dates of shear strength retention and dry state 
shear strength move in opposite directions and correlation coefficient $R=-0.60$. Remarkable variation expansion coefficient between wood and FRP could be the main reason - the stronger cohesion of interface, the more stress gathered during soaking for that. According to Figure 7, variance analysis shows that factor of power influenced both shear strength by dry and wet state test. And factors of speed and interaction influenced dry and wet state test, respectively.

\section{Fracture Toughness}

\section{1) Reduction for 4ENF Test Model}

Criterion for energy of crack propagation originated by Griffith's theory, then it developed by Iwrin-Kies in 1945 [17]:

$G_{c}=\frac{P_{c}^{2}}{2 b} \frac{\partial C}{\partial a}$

In which, $P_{c}$ is critical load, $b$ is width, $C$ is flexibility, $a$ is crack length and $G_{c}$ is critical value of shear modulus.

And according to Timoshenko's theory:

$\Delta_{L}=\frac{P S_{L}^{2}}{D}\left[\frac{-R S_{L}^{2}}{12 L}+\frac{R S_{L}}{3}-\frac{2 L}{3}+\left(\frac{2-R}{2}\right) a \times\left(1-\frac{a}{2 L}+\frac{a^{2}}{12 L^{2}}\right)\right]+\frac{P S_{L}}{D}\left[\left(1-\frac{2 L-S_{L}}{2 L}\right)\left(\frac{R S_{L}^{2}}{12}\right)-\frac{2\left(2 L-S_{L}\right)}{3}+\frac{\left(2 L-S_{L}\right)^{2}}{2}-\frac{\left(2 L-S_{L}\right)^{3}}{12}+\left(1-\frac{2 L-S_{L}}{2 L}\right)(2-R)\left(\frac{a^{2}}{4}-\frac{a^{3}}{12 L}\right)\right]$
$\Delta_{R}=\frac{P S_{L}}{D}\left\{\frac{\left(2 L-S_{L}\right)^{2}}{2}-\frac{\left(2 L-S_{L}\right)^{3}}{12}+\frac{R S_{L}^{2}}{12}-\frac{2\left(2 L-S_{L}\right) L}{3}-\frac{R S_{R} S_{L}^{2}}{24 L}+\frac{(2-R) a^{2}}{4}\left[1-\frac{2 L-S_{L}}{2 L}-\frac{a}{3 L}+\frac{\left(2 L-S_{L}\right) a}{6 L^{2}}\right]\right\}+\frac{P}{D}\left\{\left(1-\frac{2 L-S_{L}}{2 L}\right)\left[\frac{(2-R) a^{3}}{6}-\frac{2\left(2 L-S_{L}\right)^{2} L}{3}\right]\right\}$

In which, $D$ is bending stiffness and $R$ is ratio of bending stiffness with uncrack to crack part.

Because $C=\frac{\delta}{P}=-\frac{\Delta_{L}+\Delta_{R}}{2\left(P_{L}+P_{R}\right)}$ and $P_{L}=P_{R}=P / 2$, in which $P$ is total load, $P_{L}$ is left load, $P_{R}$ is right load, $\Delta_{L}$ is beam deformation at left and $\Delta_{R}$ is beam deformation at right.

$$
\begin{gathered}
\text { So, } D=E I=E \frac{b(2 h)^{3}}{12}=\frac{2 E w h^{3}}{3} \text {, and since } \\
R=\frac{E I}{E I_{d}}=E \frac{b(2 h)^{3}}{12} / E \frac{w h^{3}}{12}=8 \text { for homogeneous }
\end{gathered}
$$

material, in which, $E$ is modulus of specimen in length direction.

$$
G=\frac{9 P^{2}}{16 E b^{2} h^{3}}\left[S_{L}+a\left(1-\frac{S_{L}}{2 L}-\frac{S_{R}}{2 L}\right)\right]^{2} \quad, \quad \text { and }
$$

$$
G_{\mathrm{II}}^{4 \mathrm{ENF}}=\frac{9 P^{2} S_{L}^{2}}{16 E_{1} b^{2} h^{3}}
$$

\section{2) Specimen of 4ENF Size Design and Test}

The composite was made by proper order of wood after FRP after wood, and the interface of composites for testing should located at the middle of the height direction, so the bending stiffness should be equal between the both side of that interface. According to this basic theory, the size of 4ENF was designed as follows: height of wood above/below FRP is $20 \mathrm{~mm} / 18.58$ and of FRP is $1.4 \mathrm{~mm}$, width and length is $40 \mathrm{~mm}$ and $960 \mathrm{~mm}$, span at outside/inside is $800 \mathrm{~mm} / 400 \mathrm{~mm}$, and prefabricated length of crake is $400 \mathrm{~mm}[18,19]$. Speed of loading during test is $2 \mathrm{~mm} / \mathrm{min}$. Based on mathematical expression of (2) and critical load from test, fracture toughness result calculated as shown in Figure 8:

Variance analysis of fracture toughness is shown in Figure 9.

$S_{L}+S_{R}=2 L$, finally

\begin{tabular}{c|cccccccccccc}
\hline Number & $\mathrm{P} 1$ & $\mathrm{P} 2$ & $\mathrm{P} 3$ & $\mathrm{P} 4$ & $\mathrm{P} 5$ & $\mathrm{P} 6$ & $\mathrm{P} 7$ & $\mathrm{P} 8$ & $\mathrm{P9}$ & $\mathrm{P} 10$ & $\mathrm{P} 11$ & $\mathrm{P} 12$ \\
\hline Fracture toughness $(\mathrm{KJ} / \mathrm{m} 2)$ & 0.95 & 0.94 & 1.28 & 0.83 & 0.85 & 0.73 & 0.55 & 0.60 & 0.55 & 0.51 & 0.53 & 0.56 \\
\hline
\end{tabular}

Figure 8. Fracture toughness. 


\begin{tabular}{cccc}
\hline Test & \multicolumn{3}{c}{ Fracture toughness } \\
\hline Source of variation & Power/W & Speed/M/Min & Interaction \\
F ratio & 7.15 & 0.23 & 0.51 \\
F standard value & 3.01 & 3.40 & 2.51 \\
Significant & $\star$ & & \\
\hline
\end{tabular}

Note: $\mathrm{a}=0.05$

Figure 9. Variance analysis of fracture toughness.

Obviously, factor of power influenced the fracture toughness significantly. Besides, the groups of P10, P11 and $\mathrm{P} 12$ which are pretreated by $600 \mathrm{~W}$ power plasma showed lower fracture toughness. The maximum value of fracture toughness appeared when plasma machine's power is $300 \mathrm{~W}$ and speed is $7.5 \mathrm{~m} / \mathrm{min}$ at group P3.

\section{CONCLUSIONS}

Based on mode GIIC of 4ENF for the composite fracture toughness test, delamination properties test and shear strength test, the results showed that power and velocity interaction has significant influence on delamination properties of FRP-wood interface, and power has significant influence on shear strength and fracture toughness. Considering strength and toughness synthetically, the optimized process of plasma treatment on FRP surface could be concluded, which power consumption was $300 \mathrm{~W}$, transmission speed was $5.0 \mathrm{~m} / \mathrm{min}$. With this process, the properties of the composite interface are as following: the average shear strength at dry state was $9.46 \mathrm{MPa}, 6.49$ $\mathrm{MPa}$ at wet state, the GIIC was $0.94 \mathrm{~kJ} / \mathrm{m}^{2}$, and the average delamination ratio was $1 \%$ and $3 \%$ after soaked in normal and boiling water, which are all meet the request of standard.

\section{ACKNOWLEDGMENT}

We acknowledge the support of the China national wood/inorganic composites program (program of 863, No. 2002AA245161) team. We thank Dalian Shuanghua Factory for equipment and material provided.

\section{REFERENCES}

[1] Qing Yu, Properties and applications of FRP. China Journal of Harbin Architecture University,33(6), pp. 26-30, 2000.

[2] Plevris N, Triantafillou TC, FRP-reinforced wood as structural material. Journal of Materials in Civil Engineering, 4(3), pp. 300316, 1992.

[3] Dagher HJ, Kimball TE, Shaler SM, et al., Effect of FRP reinforcement on low grade eastern hemlock glulams (FPL-GTR-94). Report of Madison, 1996

[4] Hernandez R, Davalos JF, Sonti SS, et al., Strength and stiffness of reinforced Yellow-Poplar glued-laminated beams (FPL-RP554).Report of Madison, US Department of Agriculture, Forest Service, Forest Product Laboratory, 1997.

[5] Triantafillou TC, Deskovic N, Prestressed FRP sheets as external reinforcement of wood members. Journal of Structural Engineering, 118(5), pp. 1270-1284, 1992.

[6] Galloway TL, Fogstad C, Dolan CW, et al., Initial tests of Kevlar pre-stressed timber beams.Proceedings of the National Conference on Wood Transportation Structures, p. 2, 1996.
[7] Dolan CW, Galloway TL, Tsunemori A, Prestressed glued-laminated timber beam-Pilot study. Journal of Composites for Construction, 1(1), pp. 10-16, 1997.

[8] Brunner M, Schnueriger M, Timber beams strengthened with prestressed fibers: Delamination. Colloquium.

[9] Silva-Henriquez R, Gray H, Dagher HJ, et al., Strength performance of prestressed glass fiber-reinforced polymer, glued-laminated beams. Forest Products Journal, 60(1), 2010.

[10] Guan ZW, Rodd PD, Pope DJ, Study of glulam beams pre-stressed with pultruded GRP. Journal ofComputers Structures, 83(28), pp. 2476-2487, 2005.

[11] Zhishuang Dai, Baoyan Zhang, et al., Effect of heat treatment on carbon fiber surface properties and fiber/epoxy interface adhesion.Journal ofApplied Surface Science, pp. 8457-8461, 2011.

[12] Pengyi Zhang, Study on mechanical properties of basalt fiber reinforced structure glulam. Degree thesis. Beijing Forestry University, pp. 29-58, 2011.

[13] Oporto GS, Gardner DJ, Lopez-Anido D, Interlaminar fracture mechanics applied to bonded wood plastic composites (WPCs) and hybrid WPC-Fiber reinforced plastic composite. Proceedings of the International Convention of Society of Wood Science and Technology and United Nations Economic Commission for Europe -Timber Committee, Switzerland, WS-57, 2010.

[14] Ge J, Turunen MPK, Kivilahti JK, Surface modification and characterization of photodefinable epoxy/copper systems.Journal ofThin Solid Films, 440(1), pp. 198-207, 2003.

[15] Mall S, Johnson WS, Everett RA, Cyclic debonding of adhesively bonded composites. Report of NASA Technical Memorandum 84577, National Aeronautics and Space Administration, Washington, DC, 1982.

[16] Martin RH, Davidson BD, Mode II fracture toughness evaluation using four point bend, end notched flexure test.Journal of Plastics, Rubber and Composites, 28(8), pp. 401-406, 1999.

[17] Qiao PZ, Chen FL, On the compliance and energy release rate of generically-unified beam-type fracture specimens. Journal of Composite Materials, 45(1), pp. 65-101, 2011.

[18] Schuecker C, Davidson BD, Evaluation of the accuracy of the fourpoint bend end-notched flexure test for mode II delamination toughness determination. Journal of Composites Science and Technology, 60(11), pp. 2137-2146, 2000.

[19] Yoshihara H, Influence of span/depth ratio on the measurement of mode II fracture toughness of wood by end-notched flexure test. Journal of Wood Science, 47(1), pp. 8-12, 2001. 